From CSCW to Web 2.0:

European Developments in Collaborative Design 
David Randall • Pascal Salembier Editors

\section{From CSCW to Web 2.0: European Developments in Collaborative Design}

Selected Papers from COOP08

Springer 


\section{Editors}

David Randall

Department of Sociology

Manchester Metropolitan University

Manchester, UK

d.randall@mmu.ac.uk
Pascal Salembier

Université de Technologie de Troyes

France

pascal.salembier@utt.fr

ISBN 978-1-84882-964-0

e-ISBN 978-1-84882-965-7

DOI 10.1007/978-1-84882-965-7

Springer London Dordrecht Heidelberg New York

Library of Congress Control Number: 2010924749

(c) Springer-Verlag London Limited 2010

Apart from any fair dealing for the purposes of research or private study, or criticism or review, as permitted under the Copyright, Designs and Patents Act 1988, this publication may only be reproduced, stored or transmitted, in any form or by any means, with the prior permission in writing of the publishers, or in the case of reprographic reproduction in accordance with the terms of licenses issued by the Copyright Licensing Agency. Enquiries concerning reproduction outside those terms should be sent to the publishers.

The use of registered names, trademarks, etc., in this publication does not imply, even in the absence of a specifi c statement, that such names are exempt from the relevant laws and regulations and therefore free for general use.

Printed on acid-free paper

Springer is part of Springer Science+Business Media (www.springer.com) 


\section{Contents}

\section{Part I Awareness of Work}

1 Anticipative Awareness in a Groupware System............................. 3 Wolfgang Prinz, Elke Hinrichs, and Irina Kireyev

2 'Colour, It's Just a Constant Problem': An Examination of Practice, Infrastructure and Workflow in Colour Printing David Martin, Jacki O’Neill, Tommaso Colombino, Frederic Roulland, and Jutta Willamowski

3 Toward Regional Clusters: Networking Events, Collaborative Research, and the Business Finder

Tim Reichling, Benjamin Moos, Markus Rohde, and Volker Wulf

\section{Part II Work and Creativity}

4 Support of Collaborative Creativity for Co-located Meetings............. 65 Thomas Herrmann

5 Designing for Collective Interaction: Toward Desirable Spaces in Homes and Libraries

Peter Gall Krogh and Marianne Graves Petersen

6 Between Casual Commitment and Cross-Media Articulation: The Faith of the Napkin.

Susanne Bødker and Anja Bechmann Petersen 


\section{Part III Web 2.0 Problems and Solutions}

7 People Tagging and Ontology Maturing: Toward Collaborative Competence Management

Simone Braun, Christine Kunzmann, and Andreas Schmidt

8 Beyond Web 2.0 ... and Beyond the Semantic Web Aurélien Bénel, Chao Zhou, and Jean-Pierre Cahier

9 Engineering 2.0: Exploring Lightweight Technologies for the Virtual Enterprise.

Andreas Larsson, Åsa Ericson, Tobias Larsson, Ola Isaksson, and Marco Bertoni

10 The Interplay of Web 2.0 and Collaboration Support Systems: Leveraging Synergies.

Michael Prilla and Carsten Ritterskamp

Index 


\section{Contributors}

\section{Aurélien Bénel}

Université de Technologie de Troyes, France

\section{Marco Bertoni}

Lulea Technical University, Sweden

\section{Susanne Bodker}

Aarhus University, Denmark

\section{Simone Braun}

FZI Research Center for Information Technologies, Germany

\section{Jean-Pierre Cahier}

Université de Technologie de Troyes, France

\section{Tommaso Colombino}

Xerox Research Centre Europe (XRCE), Grenoble, France

\section{Åsa Ericson}

Lulea Technical University, Sweden

\section{Thomas Herrmann}

Ruhr-University of Bochum, Germany

\section{Elke Hinrichs}

Fraunhofer FIT, Germany

\section{Ola Isaksson}

Lulea Technical University, Sweden

\section{Irina Kireyev}

RWTH Aachen University, Germany

\section{Peter Gall Krogh}

Alexandra Institute, Århus, Denmark

Christine Kunzmann

FZI Research Center for Information Technologies, Germany 


\section{Andreas Larsson}

Lulea Technical University, Sweden

\section{Tobias Larsson}

Lulea Technical University, Sweden

\section{David Martin}

Xerox Research Centre Europe (XRCE), Grenoble, France

\section{Benjamin Moos}

University of Siegen, Institute for Information Systems, Siegen, Germany

Jacki O’Neill

Xerox Research Centre Europe (XRCE), Grenoble, France

\section{Anja Bechmann Petersen}

Aarhus University, Denmark

\section{Marianne Graves Petersen}

Aarhus University

\section{Michael Prilla}

Ruhr University of Bochum, Information and Technology Management, Germany

\section{Wolfgang Prinz}

Fraunhofer FIT, Germany

\section{Tim Reichling}

University of Siegen, Germany

Carsten Ritterskamp

Ruhr University of Bochum, Information and Technology Management, Germany

\section{Markus Rohde}

University of Siegen, Institute for Information Systems, Siegen, Germany

\section{Frederic Roulland}

Xerox Research Centre Europe (XRCE), Grenoble, France

\section{Andreas Schmidt}

FZI Research Center for Information Technologies, Germany

\section{Jutta Willamowski}

Xerox Research Centre Europe (XRCE), Grenoble, France

\section{Volker Wulf}

University of Siegen, Institute for Information SystemsSiegen, Germany

\section{Chao Zhou}

Université de Technologie de Troyes, France 


\title{
Introduction
}

\author{
David Randall and Pascal Salembier
}

The chapters in this book are extended and revised versions of selected papers from the Coop conference, which took place in Carry-Le-Rouet, near Marseille, in 2008. They reflect developments in CSCW, HCI, and related disciplines. This broad field has, for 30 years, been associated with support for complex work practices within organisations and a related concern with the relationship between traditional co-located work practices and newer, computer-mediated practices. It was founded on a critique - suggesting that new interactive or collaborative computer technologies could not be understood in the same way as prior generations of computer; that overly simplistic models of both the human actor and of the organisation would have to yield to a more complex understanding; and - perhaps most importantly that new methods and analytic approaches would be required in order to furnish this understanding. Without question, and we say this in full knowledge that the marriage has not always been a happy one (Hartman 1995) the field has been a progressive one, characterised by an inclusivity in respect of the disciplines contributing to the work and the methods that might turn out to be appropriate and relevant. The result has been an interdisciplinary approach that had been enormously influential wherever one looks. Where 'design' had previously been largely understood in terms of the need for a more scientific, or at least engineered, view it became increasingly regarded as an activity that had to reflect the situated and occasioned nature of working life. Moreover, it is a sign of the healthy state of CSCW that these changes continue to be debated, for the world changes fast and gets no simpler. The papers in this collection reflect this. They deal with some of the ways in which the sands have shifted. New 'social' technologies, with concomitant affordances, have arrived with unprecedented speed (who had heard of 'tagging', 'tag clouds', 'social bookmarking' or 'Facebook' 5 years ago?). We still struggle to understand what application they might have in the near future. Our analytic interests, and the domains we focus our attention on, continue to evolve. There have been some significant moves, such that the notion of 'awareness of work' has come to mean more than the co-located orchestration of activities to be found in, for instance, command and control centres or indeed in any single organisation. A new emphasis, perhaps also prompted by a burgeoning interest in knowledge and expertise sharing, has been evident, whereby 'awareness of work' comes to encompass the problems of expertise and knowledge in complex environments (see for instance, Ackermann 
et al. 2003) and also entails a very heterogeneous view of 'what we need to know'. Sources of complexity might include the division of labour; socially and organizationally distributed skills and expertises, and the practical problems of information seeking. Section 1 of this book deals with those issues, covering such matters as the way in which knowledge has to be both 'past' facing and 'forward' facing; how the complexities of expertise and its social distribution impinge on a workflow system for colour printing, and how required knowledge can extend well beyond the shop floor into management-related activities.

A second theme is emerging, relating to CSCW's concerns with design methodologies. It has been well-attested that traditional approaches to design have been largely based on the engineering metaphor - and substantially remain so despite the intervention of ethnographic and other strategies. More recently, however, there has been something of a sea change in respect of a recognition of creativity in design. This is a fundamental shift, for it implicates the idea that the design process, whatever it might be, is not to be understood reductively. We do not necessarily improve design by managing the steps in the process ever more tightly. This may well have to do with the move of interactive computer systems into domestic and public spaces as well as their more traditional industrial and commercial locations and what would seem to follow from that, to whit that decompositional models do not easily describe environments where 'task' is largely irrelevant (or at least, extremely difficult to define). At the same time, and not entirely surprisingly, this change in mood or sentiment has not gone unchallenged, for it implicates some radical views about the relationship between description and prescription. The concern for creativity has sometimes been understood as reflecting a postmodern sensibility, and one in which the play of possibilities, or contingencies, is best understood by a critical engagement with actors. There is no little irony in the fact that an original CSCW complaint which had to do with the fact that we knew too little about actors, or underrepresented their interests is being challenged by a variety of contested stances concerning the degree to which actors' common sense understandings of their world constitute an appropriate starting point for design-related activities (see Crabtree et al. 2009 for a range of contested positions). It is not our place to engage in this debate here, and we will limit ourselves to the observation that it has arisen at precisely the time when new technology is increasingly being developed and marketed for purposes which are not tightly coupled with work-based tasks. Regardless, it is arguably the case that we still have neither a conceptual framework for understanding creativity in design, nor methodologies which might fully reflect this transition. The papers in Section 2 represent a move forward in attempts to deal with creativity through examination of failure in the design of systems which support creative activity; through attempts to provide a more rigorous approach to conceptualisation and thirdly through a case study which examines the way in which designers and participants can reconfigure their relationship.

A third significant tendency is the joint development of the participative web (Web 2.0) and the semantic web (a natural candidate for the Web 3.0 label according to many). The idea of Web 2.0 carries a number of different, and nuanced, assumptions with it, including not least a developing interest in the way in which the Web 
can be used to support collaborations of one kind or another and the emergence of virtual communities. Of course, this burgeoning area has moved well beyond the work environments that $\mathrm{CSCW}$ has been historically associated with and now encompasses blogs, wikis, social networking sites, and so on which can, in principal, be used for any number of different purposes. At the same time, there are other, somewhat more radical, assumptions embedded in the so-called semantic web, not least Tim Berners-Lee's original ambition that symbolic information can be embedded into computer systems in such a way that semantic information can become 'machine readable'. Already processes which range from the 'tagging' associated with folksonomic applications through to fully fledged ontologies with formal and specified knowledge hierarchies embedded in them have become common. This too has a consequence for new thinking about how users might be involved in the development and population of applications. The development and use of folksonomies, ontologies and related taxonomic or tagging techniques, we suggest, has opened up in a dramatic way a new scope for the consideration of design issues as heterogeneous and creative processes. Nevertheless, this is not without challenges of its own. New relationships between designer and user are again entailed, along with new problems of conceptualising exactly who our users might be and how they might be mobilised. In Section 3, chapters deal with the various ways in which this new challenge can be met. They range through a consideration of the relationship between our historical approach to collaborative work and the challenges of the semantic and socio-semantic web through the provision of new tools: how a maturity model might help us reconfigure the design process for ontology development; how user interface issues need to be taken seriously even in the new world of social tagging; and how lightweight forms of these new applications might be taken up in the business world (Cook 2008).

The papers here, we hope, reflect the inclusivity that we earlier suggested in respect of the different disciplines which can be enlisted for design, methodologies used, and the interest in the potential of radical new technologies. The book is divided into three parts. The first part we have titled, 'Awareness of Work' and the papers within it are in their different ways attempts to deal with 'awareness' as something distinct from the glances and gazes which have informed much of our understanding of interactional awareness hitherto. Following Schmidt (2002), we take the view that 'awareness' is a deeply confused concept, one which would repay a Wittgensteinian analysis (see Martin et al. Chapter 2). That is, the various ways in which the term might be used bear a 'family resemblance' to each other but do not describe a consistent phenomenon. To put it another way, the section is titled, 'Awareness of Work' because awareness might consist in many different activities and knowledges. We need to constantly reaffirm the eclectic possibilities entailed in the term. Prinz et al. discuss the idea of 'anticipative' awareness. They suggest that groupware has, for the most part, been associated with support for 'pastoriented' activity. They argue that groupware systems can, in principle, either store and display a history of events that took place in the past or can allow users to plan in advance by seeking future notifications. As they put it, "The future event can ideally be defined to encompass any combination of specific artifacts, specific 
activities and specific members of a workspace. None of the groupware tools we analyzed, however, allows specifying actions to be carried out by workspace members until a date in the future and then automatically verifies and notifies whether they were performed within the deadline or whether they were performed late or not at all." They go on to demonstrate how this future awareness can be built into a well-known and well-used tool, BSCW, which was developed at Fraunhofer FIT.

Martin et al. examine the work done to control colour production in graphic design and printing, focusing on the reasons why practitioners do not implement 'colour managed' workflows. The technical requirements of these systems, it turns out, are beyond the capacity of most people working in the industry - both in terms of equipment set-up and knowledge. The paper then provides a critical appraisal of infrastructure and workflow as a means of supporting cooperative work in design and printing, based on an extensive ethnography conducted by the authors. Here, rather than design for awareness, the issue is 'design with awareness'. Using Star and Ruhleder's well-known notion of 'infrastructure', they identify processes of embedding, transparency, conventionality and visibility which inform the degree to which any individual will be aware of the contingencies involved in the work of another. They suggest that their study is one of the first where infrastructural issues have been analysed in an area other than scientific practice and, moreover, shows that the different parties involved are not equal partners and had little or no input into the infrastructure's design or development and therefore had no ownership. Although the authors consider the design of alternatives to be problematic, they show quite clearly that one of the major limitations of generic design is lack of awareness of work.

In the third paper in this section, Reichling et al. discuss the notion of 'regional clusters' to discuss support for an entirely different form of awareness, and that is cross-organisational. As they say, "technical approaches aiming at fostering mutual awareness and collaboration among companies in regional networks are scarce". This chapter builds on previous research which examines tools and activities to support business 'networking', based on substantial long term enquiry into joint activities in and between a number of regional companies, the paper discusses a tool called, 'Business Finder' designed to improve mutual awareness among small and medium sized businesses. Their approach is founded on arguments concerning business 'clusters' (Porter 2000) which emphasise the interconnectedness of competition and cooperation. Using an action-research perspective based on informal discussions and semi-structured interviews, they suggest a new way of both fostering collaborative ventures and designing 'shared expertise' systems for dealing with the issue of developing organisational networks.

In Section 2, as suggested above, creativity is the theme which links three papers. More specifically, collaborative creativity is an emergent theme in CSCW literature, predicated on a longstanding interest in the functioning of teams and reflecting the move away from a step-by-step, functional view of team effectiveness. Nevertheless, arguing that functional specifications of team activity ignore the essentially creative nature of team outcomes is one thing. Spelling out what creativity might be and how it might vary from one context to another (or indeed whether it can be said to have 'universal' features is quite another. Creativity, it seems to us, 
is another 'black box' which needs to be opened if we are to avoid essentially heroic, and not terribly useful formulations of the creative act (although occasional examples of attempts to relate creativity to other concrete factors do pop up in the sociology and history of art (see for instance, Baxandall 1974; Becker 1982). Thomas Herrman draws on an existing literature to derive some central features of collaborative creative activity as an initial step in this direction. As he points out, creative activity is a complex challenge because actors often have different backgrounds, thought processes and methods of self-expression and, moreover, activities are often only weakly structured and are highly flexible. Based on a series of interviews conducted with CSCW researchers, Hermann draws out a set of 'design heuristics' which include: supporting the large picture - the visualization of rich material; the malleability of shared material and stimulation of variations; support of convergence within evolutionary documentation; smooth transitions between different modes of creative collaboration; integration of communication with work on shared material, and support of role dynamics and varying modes of collaboration, thus creating what Hermann terms a, 'conceptual architecture' which might aid in disentangling the similarities and differences to be found in various sited of collaborative creative activity.

Krogh and Petersen, from the Alexandria Institute and Aarhus University in Denmark, take a different view of the creative process, and aim to show how 'users' can be a part of it in ways that are sometimes unanticipated. Of course, there is a long tradition in Participatory Design and elsewhere of user involvement but here the involvement of the user takes a new and creative form. The authors present an approach to design for collaborative co-located experiences among people sharing collective resources for controlling interfaces in places like libraries and the home. They claim, following Hindmarsh et al. (2005) that it is still the case that few systems are designed to support interaction in these locations and a shift in emphasis towards, "what desirable place or situation are we forming together?" is necessary.

In this vision, people become designers in and through their playful interactions with each other and through prototypical systems placed in real-world contexts. This ludic vision, which has something in common with Bill Gaver's work (Gaver 2001, 2002), entails users creatively making technology at home in their world. To illustrate these themes, the authors present two design case studies, one in the context of a public library and one in a home context, where technologies are put in place with the explicit intention of engaging users collaboratively.

Bodker and Bechman Petersen, also from Aarhus in Denmark, emphasise the empirical issues surrounding support for creative activities by analysing the way in which a new collaborative technology, 'Napkin', was introduced to support creative, integrative, cross-media production. This evaluative study shows how a complex technology designed to support news reporters, failed. They provide a detailed examination of the reasons for that failure, and in particular look at the different worldviews and commitments on the part of, for instance, journalists and editors. In a similar way to Martin et al. in Chapter 2, they point to the different and incommensurate practices of various parties to a creative activity- the production of multimedia news reports for several outlets including, 'radio, TV, web, a daily newspaper 
and several additional products'. In this way, the paper is a valuable reminder of what we have suggested above- that even when we are dealing with new and more creative endeavours, the same careful, empirically based evaluations will be necessary. As Bodker and Bechman Petersen point out, regardless of the kind of activity involved, there will necessarily be some kind of articulation work entailed (Strauss; Schmidt \& Bannon, 1992) and that there is a considerable overhead to this when different groups have different narrative visions, as in this case.

Section 3 deals with various features of the move to "new forms of Web" (participative and semantic). We have argued above that the move to machine readable semantic information is hugely ambitious (and arguably foolhardy) but to turn our backs on semantic web would be foolish and to neglect further prospects in ontologies, intelligent agents and the like will not make them vanish into air. It seems to us that CSCW has an enormous amount to contribute to this evolving technology. Not least, and CSCW practitioners are well aware of this tendency, many of the hard-won lessons for design concerning the importance of solid, careful and detailed empirical work as a tool in the design toolkit are often ignored in the rush to do 'cutting edge' design. Nevertheless, in the context of Web 2.0 and semantic Web it does seem to us to be important that we reiterate that the empirical studies associated with design work which first came to prominence in CSCW existed to rectify a perceived deficiency - a lack of information about the ordinary, practical ways in which people go about their business. To our knowledge, no serious ethnographer has ever suggested that the results of such enquiries constitute a solution to design problems- rather that such studies are a good place to start in considering what kinds of problem design work may encounter. That there may be different analytic policies involved in the apparently simple business of doing empirical work- and how empirical results relate (or not) to theoretical issues - is beyond question, and these policies may not all serve the same purpose. Nevertheless, there is a danger that in inhabiting the brave new worlds of Web 2.0 and semantic Web, practitioners neglect the importance of the user, howsoever s/he is construed and, as a function of this, neglect the business of evaluating what we have achieved. By way of example, there is at least a 10 year history of 'ontology-based design' now. This is perhaps the most fully-fledged and ambitious example of a semantic application in Web technology. Ontologies in their most mature and widely-used forms are in the main associated with the bio-informational sciences, and the Gene Ontology (GO) would probably be the best known. It is surprising, then, to discover that approaches to ontology-building largely duplicate the top-down engineering assumptions of software engineering from 20 years ago (Gomez-Perez et al. 2004), and that there are few if any prolonged and systematic empirical studies of use (but see Lin et al. 2008). This, we suggest, is a critical omission since the successful application of various kinds of semantic engine will depend in large part on the domains in which they are applied and what we know about them. Not least, even in the most 'scientific' of domains, it turns out that there are more disputes about terms and their logical relations that one might expect. It follows that, in more heterogeneous contexts, those problems are likely to be magnified. Braun, Kunzmann and Schmidt, working at the FZI Research Center for Information 
Technologies in Karlsruhe, Germany propose ways to deal with the design and implementation of an ontology for organisational purposes, including effective resource allocation, knowledge management and human resource development. We know already from a number of studies in both CSCW and elsewhere that knowledge management projects of this kind often fail, in part because competence is not well described and has a dynamic quality. A range of organisational barriers sometimes lead to incomplete and outdated information, and because the maintenance of knowledge bases is extremely difficult (for the reasons that Grudin originally pointed out) eliciting information for ontology-construction is a non-trivial task in this context. Braun et al. argue that, 'a lack of participation of all employees has been one of the key problems. To overcome this, we propose a collaborative approach based on Web 2.0-style people tagging and complement it with communitydriven ontology engineering methods.' they go on to suggest a combination of Web 2.0 'bottom-up' approaches using folksonomic processes and 'expert' led top-down approaches to produce an Ontology Maturation Model.

Larsson et al. working at Lulea University in Sweden, continue with the general theme of how Web 2.0 applications are likely to impact on organisational matters through a consideration of what they call, 'Engineering 2.0'. In a virtual enterprise setting, they argue, it becomes increasingly important to make sure that knowledge and expertise created in one discipline, domain or company is correctly understood and quickly utilised by other actors in the value chain. Virtual enterprises are those which exist for specific purposes, and are not defined in terms of buildings and personnel. They often consist of, for instance, groups which may, in other circumstances, be competitors. It follows, therefore, that if these groups are temporary and dynamic then the overhead of setting up technology support has to be taken very seriously, as do the problems of information security. The authors suggest that 'hard' engineering data is already well-supported by, for instance, CAD packages and so on, but that, '... knowledge work also has a social dimension, e.g., learning and experiencing. The assessment of the result from a number of distinct computer analyses, i.e., 'putting two and two together', and what engineers know by experience influence many decisions in product development, but this kind of design reasoning is usually not made visible in the same way as technical product information.'

They then explore the use of 'lightweight' technologies for supporting the creative use and re-use of information by design teams in this context.

In their paper Benel et al. introduce the notion of the "socio-semantic Web" as "the confluence of knowledge engineering and CSCW", and as an alternative to the formal approach of semantics promoted by the semantic Web. According to the authors, if the new web aims at supporting cooperation inside and between communities it has to be built upon a social-oriented view of ontologies rather than on a computational one. This view has direct effects on the delimitation of relevant theoretical objects (intersubjectivity, collaborative construction of meaning, trust between the actors, and so on) and on the nature of the technological commitment (semi-formal ontologies, micro-social tagging, visualisation of individual viewpoints, etc). This approach gave birth to a set of dedicated tools including Agorae, a web platform which supports the collaborative building of topic maps. 
In the paper, the authors suggest methods for developing social tagging by incorporating multi-viewpoints, multi-tags selection and tag relations to produce interfaces which have a more directed purpose than just maximising utility for 'crowds' of user. An illustration drawn from a study performed in the domain of scientific archive is presented in more detail.

Prilla and Ritterskamp question whether the CSCW conception of collaboration support remains viable in the age of Web 2.0. As they point out, the success of lowoverhead web-based technologies like Wikis seems to support the argument that web-based architectures provide specific benefits, such as simplicity of usage, immediate feedback on UI and structural level and feedback on user contributions (e.g. Grudin 2006). As they say, "Web 2.0 orchestrates available technology in a way that encourages users to participate actively as its architecture of participation helps to balance effort and benefit even in work-related settings." Nevertheless, they are optimistic for the future of collaboration support tools because they see no automatic translation between one set of functions, designed for mass collaboration and another, designed for enterprise collaborations. The similarities and differences to be found in the distinction between collaboration support systems and Web 2.0 applications reside, in their view, in three main dimensions: goal and work orientation, communication and coordination among peers in groups and playfulness and user experience. and argue forcefully that new Web 2.0 tools complement and enhance the prospects for CSCW applications. They demonstrate through an examination of prototypes how successful strategies for combining the two can be found.

Overall, then, it is clear that the themes and perspectives that emerged in CSCW some 30 years ago have not gone away. At the same time, they are being progressively transformed as new technologies appear and as we adopt new methods for working out what to do with them. We argued at the start that CSCW has been enormously influential in a variety of fields, not all of them technology-related. The ethnographic 'turn' largely inspired by CSCW concerns has been appropriated and used in any number of interdisciplinary areas and shows no sign of exhausting its uses. Even so, new and creative versions of investigative technique are common and the papers in this collection demonstrate that fact. Equally, the advent of radical new technology provides a new lease of life and prompts lively discussion about the new relationships to be discovered therein. All in all, we hope these papers demonstrate the health of CSCW and its continued growth and maturity.

\section{References}

Ackermann, M., Pipek, V. and Wulf, V. (eds.) (2003) Sharing Expertise: Beyond Knowledge Management, Cambridge, MA: MIT Press

Baxandall, M. (1974) Painting and Experience in Fifteenth-Century Italy: A Primer in the Social History of Pictorial Style. Oxford Paperbacks: Oxford

Becker, H. (1982) Art Worlds. Berkeley: University of California Press

Cook, N. (2008). Enterprise 2.0 - How social software will change the future of work: London: Gower 
Crabtree, A., Button, G., Rodden, T. and Tolmie, P. 2009, Proceedings of CHI 2009, Boston, Mass: ACM Press

Dourish, P. (2006) Implications for design? Proceedings of the SIGCHI conference on Human Factors in computing systems, Montreal, Canada

Gaver, W. (2001) Designing for ludic aspects of everyday life. Ercim News. No.47. www. ercim. org/publication/Ercim_News/enw47/gaver.html

Gaver, W. (2002) Provocative Awareness, Computer Supported Co-Operative Work: The Journal Of Collaborative Computing, Amsterdam. 11. 47. 5-93.

Gomez-Perez, A., Fernandez-Lopez, M. (2004) Ontological Engineering: With Examples from the Areas of Knowledge Management, E-Commerce and the Semantic Web, Springer

Grudin, J. (1988) Why CSCW Applications fail: Problems in the Design and Evaluation of organizational Interfaces. Proceedings of CSCW, 88. Portland, Oregon: ACM Press. 85-93

Grudin, J. (2006) Enterprise Knowledge Management and Emerging Technologies. Proceedings of the 39th Annual Hawaii International Conference on System Sciences. HICSS'06

Hartman, H. (1995) The Unhappy Marriage of Marxism and Feminism: Towards a more progressive union, in V. Lippit. Radical Political Economy. M.E.Sharpe

Hindmarsh J., Heath C., Vom Lehn D., Cleverly J. (2005) Creating Assemblies in Public Environments: Social Interaction, Interactive Exhibits and CSCW, Computer Supported Cooperative Work (CSCW). Vol 14 No 1

Lin, Y-W., M. Poschen, R. Procter, J. Kola, D. Job, J. Harris, D. Randall, W. Sharrock, J. Ure, S. Lawrie, A. Rector and C. Goble, C. (2008) Ontology building as a social-technical process: a case study. Oxford e-Research Conference, Oxford, UK. September.

Porter, M. E. (2000) Locations, Clusters, and Company Strategy. In: Clark, G. L.; Feldman, M. P.; Gertler, M. S. (Eds.): Oxford Handbook of Economic Geography. Oxford University Press: New York, S. 253-274.

Schmidt, K. (2002) The Problem with Awareness: Introductory remarks on awareness in CSCW, Computer Supported Co-Operative Work: The Journal Of Collaborative Computing, Amsterdam Vol 11 (3-4) Springer. 285-298

Star S. L., and Ruhleder, K. (1996) Steps toward an ecology of infrastructure: Design and access for large information spaces, Information Systems Research 7(1). 111-134

Strauss, A. (1988) The Articulation of project Work. The Sociological Quarterly, Vol. 29 No.2. $163-178$ 